Interestingly, the previously reported patient with a different but overlapping deletion of chromosome 12 long $\operatorname{arm}(q 13.3-q 21.1)$ and the subject of this report have only a few features in common (table). The deletion in each includes the portion $12 \mathrm{q} 13.3$ to $\mathrm{q} 21.1$. It is unclear whether the small difference in the portion of $12 \mathrm{q}$ deleted accounts for the fact that they do not resemble each other to a greater extent. The delineation of a syndrome associated with interstitial deletion of $12 \mathrm{q}$ must await reports of additional cases.

The detection of subtle chromosome abnormalities such as this show the need for minimum standards for routine studies of those at risk for chromosome abnormalities. Our impression is that these minimum standards should include well banded chromosomes of the 450 to 550 band stage.

M S Watson, L McAllister-Barton, M J Mahoney, AND W R BREG

Departments of Human Genetics and Pediatrics, Yale University School of Medicine, New Haven, Connecticut, USA.

\author{
Reference \\ ${ }^{1}$ Meinecke P, Meinecke R. Multiple malformation syndrome \\ including cleft lip and palate and cardiac abnormalities due to an \\ interstitial deletion of chromosome 12q. J Med Genet 1987; \\ 24:187.
}

Correspondence to Dr M S Watson, Department of Pediatrics, Washington University School of Medicine, 400 South Kingshighway Boulevard, St Louis, Missouri 63110, USA.

\section{A third case of de novo partial trisomy $4 p$}

More than 30 cases of partial trisomy $4 p$ have been described. ${ }^{1}$ The majority of these cases were the result of a parental translocation and only two cases had parents with normal karyotypes.

The proband was born spontaneously at term after a pregnancy complicated by mild toxaemia. Paternal age was 32 years and maternal age 29 years. Birth weight was less than $2500 \mathrm{~g}$. Failure to thrive was mentioned in the early medical records, but generally physical health has been good. His height developed along the 25 th centile. At 16 years of age he started to grow excessively with a final height, at the age of 21 , of $201 \mathrm{~cm}$. Psychomotor development has always been slow and speech never developed.

At the age of 23 years the proband was examined by one of us (JWEO). He was a tall, restless, mentally deficient man with an occipitofrontal circumference of

Received for publication 12 August 1988.

Revised version accepted for publication 24 October 1988.

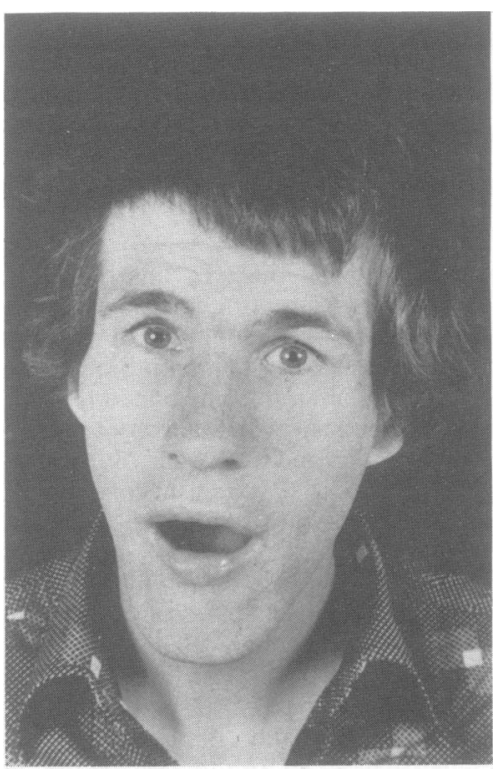

FIG 1 The facial features of the proband at 21 years of age.

$53 \mathrm{~cm}(<-2 \mathrm{SD})$. His face (fig 1) was elongated and rather narrow with a prominent glabella, heavy eyebrows with synophrys, a mild mongoloid slant, midfacial hypoplasia, bulbous nose, mild macrostomia, high palate, and a long, receding chin. The ears showed a slightly prominent antihelix and attached earlobes. There were cubiti valgi, bilateral short third to fifth metacarpals, short firs metatarsals, and a short fourth metatarsal on the left Secondary sexual characteristics were normal, although the testes were rather small in size.

Examination by an endocrinologist provided no additional information; ophthalmological examination was normal. The EEG showed diffuse abnormalities, especially of the brain stem. Radiographs showed a normal skull, shortened metacarpals, and hypoplastic first ribs. The degree of mental deficiency was considered to be moderate, but was difficult to assess because of behavioural problems.

Cytogenetic analysis was performed on peripheral blood lymphocytes, using GTG and RBA banding techniques. Fourteen cells from the proband were examined and showed 46 chromosomes in all cells with a partial duplication of chromosome $4: 46, X Y, \operatorname{dup}(4)(\mathrm{p} 12 \rightarrow \mathrm{p} 15.2)$ (fig 2). The parental karyotypes were normal.

Apart from the excessive height the phenotypic abnormalities of the proband are consistent with trisomy $4 p$, as reviewed by Gonzalez et al. ${ }^{1}$ Only two cases of de novo interstitial trisomy $4 p$ have been reported. In a third case, ${ }^{2}$ a chromosome 1 was also involved and therefore, in the strictest sense, this was not isolated trisomy $4 \mathrm{p}$.

We thank J M N Hoovers, Cytogeneticist, for his advice, 


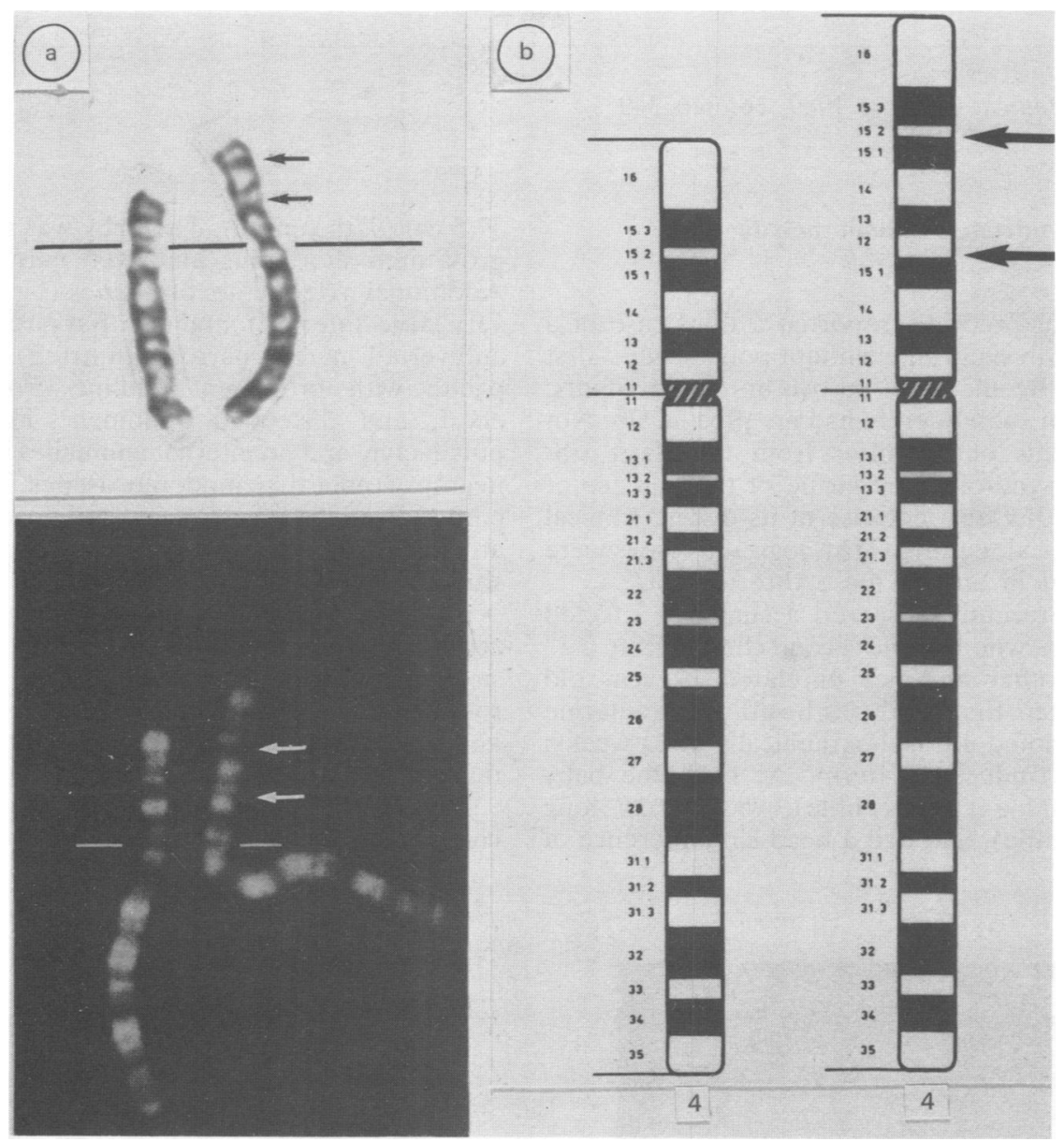

FIG 2 (a) Partial karyotype of the proband. (Above) GTG banding. (Below) RBA banding. The arrows indicate the duplicated segment. (b) Idiogram of chromosome 4.

Drs A $\mathbf{H}$ Wissel and $L$ van Dorp for providing recent medical data, and $M$ Stam-Johan, $R$ Lutgerhorst, and W van Est for technical assistance.

J W E OORThuYs*, K B J GersSen-SChOorl ${ }^{\dagger}$, J M de Pater $\ddagger$, and $H$ F de France $\ddagger$ *Institute of Human Genetics, University of Amsterdam, Amsterdam; †Regional Pathology Laboratory, Department of Cytogenetics, Enschede; and $¥$ Clinical Genetics Centre, State University, Utrecht, The Netherlands.

\section{References}

' Gonzalez GH, Sommer A, Meisner LF, Elejalde BR, Opitz JM. The trisomy $4 p$ syndrome: case report and review. Am J Med Genet 1977:1:137-56.

2 André MJ. Aurias A, de Berranger P, Gillot F, Lefranc G, Lejeune $J$. Trisomie $4 p$ de novo par isochromosome $4 p$. Ann Genet (Paris) 1975;19:127-31.

Correspondence to Dr J W E Oorthuys, Institute of Human Genetics, Amsterdam University, Academic Medical Centre, gebouw M1, Meibergdreef 15, 1105 AZ Amsterdam, The Netherlands. 